\section{Circulating Soluble Antigens and Antibody in Schistosomiasis}

\author{
M. A. MADWAR, A. VOLLER
}

British Medical fournal, 1975, 1, 435-436

\section{Summary}

Some patients with Schistosoma mansoni and S. haematobium infections were shown to have soluble schistosomal antigen in their plasma. Antibody to this antigen and to other antigens of adult worms were also present. These findings may be relevant to schistosomalrelated immune-complex disease, especially the nephrotic syndrome.

\section{Introduction}

Andrade and Queiroz (1968) first reported that Schistosoma mansoni infections were sometimes accompanied by renal lesions. Later work on kidney biopsy specimens from such patients indicated that there were glomerular deposits of IgG and IgM, and ultrastructural studies showed focal electron-dense areas (Silva et al., 1970). Queiroz et al. (1973) then described the kidney involvement as a nephrotic syndrome with membranoproliferative glomerulonephritis and nonselective proteinuria. Experimental infections of mice and hamsters with $S$. mansoni also showed immunoglobulin and electron-dense deposits in the kidneys (Hillyer and Lewert, 1974; Andrade and Susin, 1974). El-Said et al. (1973) reported the nephrotic syndrome in $S$. haematobium infections.

Taken together these studies strongly suggest that there are soluble immune complexes formed in schistosomiasis and that they may be deposited in the glomeruli, leading in some instances to the nephrotic syndrome. To date, however, the soluble antigen, which must be a necessary prerequisite for immune-complex disease, has not been found in the kidneys or plasma.

We report the finding of circulating soluble antigen and antibody in human schistosomiasis.

\section{Materials and Methods}

A soluble extract of adult $S$. mansoni worms was used as antigen. This reference extract was prepared by grinding with saline adult worms harvested from infected hamsters. It was stored at $-20^{\circ} \mathrm{C}$ until used. A reference antiserum to adult $S$. mansoni worms was prepared in rabbits by injecting the ground worms into the rabbits with Freund's adjuvant.

The gel-diffusion tests were set up on slides in $1 \%$ agarose made up in barbiturate buffer $\mathrm{pH} 8.6$. Wells were refilled when necessary. The slides were examined for the presence of precipitation lines 24 48, and 72 hours after the reactants were added to the wells. Finally, the gels were dried and stained to provide permanent records.

London School of Hygiene and Tropical Medicine, London W.C.1 M. A. MADWAR, M.D., World Health Organization Fellow, Medical Unit A. VOLLER, D.SC., Senior Lecturer, Department of Clinical Tropical Medicine

\section{ANTISERA}

Sera from a group of patients with active $S$. mansoni or $S$. haematobium infections were studied. Most of the patients were resident in Egypt; others were seen in London at the Hospital for Tropical Diseases.

(1) The sera were tested against soluble $S$. mansoni adult worm extract to see whether they contained antibody. (2) The sera were tested against the rabbit antiserum to $S$. mansoni to determine whether they contained soluble schistosomal antigens. (3) The sera were tested against each other to indicate any soluble antigen-antibody systems present. (4) All positive sera were set up adjacent to the reference preparations to determine identity relationships with the $S$. mansoni antigen and antiserum reference preparations. (5) Normal sera from 12 Europeans who had no schistosomiasis were tested against the rabbit antiserum to $S$. mansoni and against soluble $S$. mansoni extract.

\section{Results}

The gel-diffusion tests showed that most patients with $S$. mansoni infections (table) had serum antibody which reacted with reference $S$. mansoni soluble antigen extract. About two-thirds of the $S$. haematobium patients (table) gave precipitin lines with that extract. The rabbit antiserum to $S$. mansoni gave precipitation lines with the sera from about half of the $S$. mansoni patients (table) and about one-third of the $S$. haematobium patients (table). This indicated the presence of soluble circulating antigen in these patients.

The strongest reactions were, of course, obtained between the reference rabbit anti-S. mansoni serum and the reference soluble $S$. mansoni antigen preparation. In this system four lines were obtained. The human sera which reacted with the $S$. mansoni antigen gave one to three lines, and these showed a reaction of partial identity with the reference rabbit antischistosomal serum. The human sera containing antigen gave a reaction of partial identity with the soluble antigen of $S$. mansoni when they were tested against the rabbit antiserum to $S$. mansoni. One of the sera from an $S$. haematobiuminfected patient reacted with the sera from four other patients, three of whom had $S$. haematobium infections and one an $S$. mansoni infection. Another serum, also from an $S$. haematobium case, reacted with the serum from an $S$. mansoni patient. In all these instances of sera reacting against each other only one precipitin line was detected. This was shown,

Results of Gel-diffusion Tests for Schistosomal Antigen and Antibody in Sera from 22 Egyptians with Proved Current S. haematobium Infection.

\begin{tabular}{|c|c|c|c|}
\hline \multicolumn{2}{|c|}{ Patients } & \multirow{2}{*}{$\begin{array}{l}\text { No. of Antibody } \\
\text { Precipitin Lines }\end{array}$} & \multirow{2}{*}{$\begin{array}{l}\text { No. of Antigen } \\
\text { Precipitin Lines }\end{array}$} \\
\hline $\begin{array}{c}\text { Age } \\
\text { (Years) }\end{array}$ & Sex & & \\
\hline $\begin{array}{l}10 \\
10 \\
12 \\
12 \\
12 \\
15 \\
15 \\
20 \\
20 \\
20 \\
20 \\
22 \\
22 \\
22 \\
23 \\
25 \\
30 \\
30 \\
33 \\
38 \\
45 \\
45\end{array}$ & 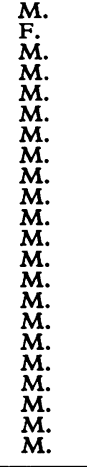 & $\begin{array}{l}2 \\
1 \\
\\
2 \\
1 \\
1 \\
1 \\
1 \\
1 \\
3 \\
2 \\
2 \\
2 \\
2 \\
\\
1\end{array}$ & $\begin{array}{l}2 \\
1 \\
1\end{array}$ \\
\hline \multicolumn{2}{|c|}{ No. positive for test } & 13 & 7 \\
\hline
\end{tabular}


by tests set up in adjacent wells, to give a reaction of partial identity with the reference antiserum $S$. mansoni and the reference $S$. mansoni antigen. Normal sera did not react when diffused against reference antiserum $S$. mansoni and reference $S$. mansoni antigen.

\section{Discussion}

As expected, many of the sera from the patients with schistosomiasis contained antibody to $S$. mansoni adult worm extracts. Not every serum contained antibody, a finding discussed by Kagan (1968). Antibody was more commonly detected in the $S$. mansoni patients, but this may have been because we used the homologous $S$. mansoni antigen for the tests. Though this antigen cross-reacts with $S$. haematobium antibody it may be less effective in this heterologous system.

The novel finding was the demonstration of circulating soluble schistosomal antigen in the patients' sera, particularly sera from the patients infected with $S$. mansoni. This is not too surprising when one considers that the adult worms are located in the blood stream. Interestingly, antibody to the circulating antigen was also demonstrable. Under the conditions which we employed, antigen bound up in immune complexes would not be demonstrable. Only when antigen was present $(a)$ in the absence of its reciprocal antibody-for example, early in infection-or $(b)$ in excess simultaneously with immune complexes would it be shown by our geldiffusion tests. Of course, under conditions of antigen excess immune complexes are most likely to be formed and then deposited in the glomeruli, leading to the renal complications reviewed above. The formation of such immune complexes in schistosomiasis may be a common transient event followed by spontaneous resolution in most cases. Probably only a minority go on to develop the chronic immune complex disease, which may then include an autoimmune element, possibly with antibodies to the original immune complex or altered host tissue. This would account for the difficulty in demonstrating schistosomal antigen in the kidneys of the patients with developed nephrotic syndrome.

In addition to their importance in immunopathology the presence of circulating antigens and immune complexes might be expected to interfere with serological tests designed to measure antibody to schistosomes. This may be the reason for the fairly common false serological negatives especially encountered in young patients with schistosomiasis.

We think that this work deserves to be extended to include longitudinal observations on patients with the disease before and after treatment. Longitudinal studies on induced infections in animals could also answer some of the questions about the origin, time course, and fate of the soluble circulating antigens of schistosomes.

We are grateful to Professor A. W. Woodruff for his constant encouragement and advice, and to Dr. D. Bidwell, who supervised the gel-diffusion tests. The reference antiserum to adult $S$. mansoni worms was kindly donated by Dr. John Kusel.

\section{References}

Andrade, Z. A., and Queiroz, A. C. (1968). Revista do Instituto de medicina tropical, Săo Paulo, 10, 36.

Andrade, Z. A., and Susin, M. (1974). American fournal of Tropical Medicine and Hygiene, 23, 400.

El-Said, W. M., Abou-Gabal, I., and Sabbour, M. (1973). Ain Shams Medical fournal, 24, 259.

Hillyer, G. V., and Lewert, R. M. (1974). American fournal of Tropical Medicine and Hygiene, 23, 404.

Kagan, L. G. (1968). Bulletin of the New York Academy of Medicine, 44, 262. Queiroz, A. C., et al. (1973). American fournal of Tropical Medicine and Hygiene, 22, 622.

Silva, L. D., et al. (1970). Bulletin of the World Health Organization, 42, 407.

\section{MEDICAL MEMORANDA}

\section{Post-transfusion Purpura Associated with Unusual Platelet Antibody (Anti-P1B1)}

\author{
E. F. VAUGHAN-NEIL, S. ARDEMAN, G. BEVAN, \\ A. C. BLAKEMAN, W. J. JENKINS
}

British Medical fournal, 1975, 1, 436-437

Post-transfusion purpura is a rare cause of thrombocytopenia occurring in women about a week after blood transfusion. Almost all patients with this disorder have had pregnancies or have had blood transfusions some years earlier (Shulman it al., 1961; Morrison and Mollison, 1966; Cimo and Aster, 1972).

Edgware General Hospital, Middlesex HA8 0AD

E. F. VAUGHAN-NEIL, B.M., B.CH., Medical Registrar

S. ARDEMAN, B.M., PH.D., Consultant Haematologist
G. BEVAN, M.B., M.R.C.P., Consultant Physician

North-east Metropolitan Regional Blood Transfusion Centre, Essex CM15 8DP

A. C. BLAKEMAN, F.I.M.L.T., Chief Technician

W. J. JENKINS, M.D., F.R.C.PATH., Director
The condition is usually self-limiting though one death from intracranial haemorrhage has been reported (Gockerman and Shulman, 1973). The aetiology is uncertain but all patients tested have had circulating antibodies to a transfused platelet antigen absent from their own platelets.

We report a case of post-transfusion purpura which differed from other cases in that the platelet antigen was $\mathrm{PL}^{\mathrm{B1}}$ and there was a rapid improvement in the platelet count and clinical state after treatment with massive doses of corticosteroids.

\section{Case Report}

A woman aged 79 was admitted to hospital on 7 October 1973 for cholecystectomy. Preoperatively her haemoglobin was $14.1 \mathrm{~g} /$ $100 \mathrm{ml}$, W.B.C. $7800 / \mathrm{mm}^{3}$ and M.C.V. 90 fl. Platelets were present in normal numbers on a blood film and liver function, urea, and electrolytes were normal.

On 10 October cholecystectomy with exploration of the common bile duct was carried out; a gall stone obstructing the duct was removed and a $\mathrm{T}$-tube drain inserted. During the operation the patient was transfused with 2 units of group A, Rh-positive blood though the blood loss was not excessive and haemostasis was normal. On the first postoperative day the haemoglobin was 15.7 $\mathrm{g} / 100 \mathrm{ml}$, the W.B.C. $14800 / \mathrm{mm}^{3}$, and the platelets appeared normal on the blood film. She received two intramuscular injections of pentazocine $60 \mathrm{mg}$ and one of metoclopramide $10 \mathrm{mg}$ postoperatively.

On 17 October generalized purpura and bleeding from the operation wound and T-tube developed. The blood pressure became 